\title{
TERMINATIO E LIMITATIO: INAUGURAÇÃO, FUNDAÇÃO E CENA RITUAL NA REPÚBLICA ROMANA
}

\author{
Terminatio and limitatio: \\ inauguration, foundation and ritual scene \\ in Roman Republic
}

Claudia Beltrão da Rosa*

\begin{abstract}
RESUMO
Na religião pública e na legislação romana, a organização do espaço determinava a localização da vida pública. Magistrados definiam fronteiras e organizavam territórios em situações específicas, além de orientarem seu uso, num sistema que envolvia e remetia a rituais religiosos. Remeter-nos-emos a procedimentos rituais identificados para as fundações de coloniae Latinae entre 334 e 218 a.C., comparando-as a ações rituais do colégio dos áugures, cujas tarefas envolviam a definição e a manutenção das fronteiras entre o divino e o humano, o interior e o exterior, protegendo a urbs fundada, buscando uma via de acesso à compreensão dos fundamentos da lógica espacial romana.
\end{abstract}

Palavras-chave: religião romana; religio publica; rituais e espaço.

\begin{abstract}
In public religion and Roman law, the organization of space determined the location of public life. Magistrates defined boundaries and organized territories in specifics situations, and, in addition, defined their uses in occasions in which religious rituals were involved. We will refer to ritual procedures identified to the foundations of coloniae Latinae between 334 and $218 \mathrm{BC}$, compared to the ritual actions of the college of augurs, whose tasks involved the definition and maintenance of boundaries between the divine and human, protecting the founded urbs, in order to understand the spatial logic of the Romans.
\end{abstract}

Keywords: Roman religion; religio publica; rituals and space.

" Professora Associada de História Antiga do Departamento de História e do PPGH da Universidade Federal do Estado do Rio de Janeiro (UNIRIO). Doutora e Mestre em História. 


\section{Introdução}

sileteque et tacete atque animum aduortite, audire iubet uos imperator

(Plauto. Poen, 3-4)

Com essa chamada, que demanda o silêncio e a atenção dos espectadores para que ouçam seu "comandante", Plauto inicia sua comédia Poenulus ("O pequeno cartaginês"), datada do início do século II a.C. ${ }^{1}$. Poucos versos depois, ainda no Prólogo, vemos a seguinte frase: "Agora, quero retornar ao argumento, que vocês saberão por mim mesmo. Seus lugares, seus limites, suas fronteiras vou agora determinar, e para tal fui nomeado finitor" (Plauto. Poen. 46-49) ${ }^{2}$.

O dramaturgo, seguindo seu "papel”, diz que dividirá a peça do mesmo modo pelo qual os finitores dividiam um território, parodiando ações rituais dos magistrados, instruindo o praeco a ordenar silêncio à multidão e a todos (praeco, lictores e a audiência) a imitar fórmulas verbais que provavelmente eram conhecidas e, com isso, o riso é estimulado.

O teatro romano é um veículo para conhecermos, em parte, algo das "vozes" dos rituais e elementos de suas performances. Vemos, no prólogo do Poenulus, as chamadas, as ordens de silêncio, as fórmulas rituais, as duplicações e respostas dos assistentes/espectadores, refletindo a importância do ritual e permitindo uma apreciação das ações (drama) que enriquece, para nós, a compreensão de elementos da vida social romana, pois uma encenação só é significativa no interior de tradições e de práticas sociais. Encenadas no palco, palavras, gestos e convenções a que todos estavam habituados, ou de que tinham notícias, sobrelevavam a sensibilidade dos espectadores para a cena teatral. Plauto nos apresenta um finitor em cena, organizando os limites da encenação como o magistrado organizava o território e ordenava seu uso pelos seres humanos. Com o dramaturgo, entramos em plena cena governamental da Roma médio-republicana, e uma investigação das ações

1 Por escapar de nossos propósitos, não discutiremos a datação do Poenulus. Ressaltamos, contudo, o contexto das Guerras Púnicas e da ampliação territorial dos domínios romanos nos argumentos de várias das comédias plautinas.

2 Ad argumentum nunc uicissatim uolo remigrare, ut aeque mecum sitis granures. Eis nunc regiones, limites, confinia determinabo: ei rego finitor factussum (Plauto. Poen. 46-49; tradução da autora). 
governamentais romanas precisa lidar com práticas rituais, conceitos e termos da religio publica. Entramos, portanto, em plena cena ritual.

Busquemos uma definição útil do conceito de ritual:

Ritual é um sistema culturalmente constituído de comunicação simbólica. É constituído de sequências padronizadas e ordenadas de palavras e atos, frequentemente expressos em media múltiplos, cujo conteúdo e arranjo são caracterizados em vários graus pela formalidade (convencionalidade), estereotipia (rigidez), condensação (fusão) e redundância (repetição) ${ }^{3}$.

Tal definição remete ao modus operandi do ritual, mas podemos nos perguntar: comunicação de quê? Interessa-nos aqui um tipo de rito público. Desse modo, observemos outra definição, igualmente útil para nossos propósitos, na qual os ritos públicos são:

[...] uma forma de comunicação simbólica, disseminando uma representação idealizada da comunidade, de sua liderança, suas unidades constituintes, as relações necessárias entre elas e o lugar de tudo e de cada coisa no mundo ${ }^{4}$.

As performances rituais são ocasiões públicas significativas para a pesquisa histórica. Nelas, encenam-se ações e conteúdos considerados importantes pelos participantes, sejam oficiantes ou espectadores, que estreitam solidariedades, criam e consolidam hierarquias e padrões de ordenamento social, definem formas e modos de uso dos bens móveis e imóveis, etc. Tudo isso fundamentado em valores e crenças, em cosmovisões, imagines mundi que, pelo ritual, são expressos, visualizados, vivenciados. Tornam-se realidades. Do mesmo modo, rituais manifestam um corpo de conhecimentos e de tradições que guiam e comandam as ações do grupo, determinando os atores apropriados, as ações necessárias, os lugares adequados e as formas requeridas pelas quais tanto o ritual quanto as ações públicas que instituem devem ocorrer.

3 TAMBIAH, S. Culture, Thought and Social Action: an Anthropological Perspective. Cambridge-MA: Harvard University Press, 1985, p. 128.

4 GARGOLA, D. J. Lands, Laws and Gods. Magistrates and Ceremony in the Regulation of Public Lands in Republican Rome. Chapel Hill: University of North Carolina Press, 1995, p. 6. 
Plauto nos traz uma paródia de um magistrado romano em ação e, se podemos pôr em causa muitas das descrições ou remetimentos a rituais presentes na documentação textual, esta nos permite, minimamente, entrever o modo como o escritor - e, de certo modo, seu público - percebia os procedimentos dos magistrados.

Nosso conhecimento dos rituais, e especificamente dos rituais de terminatio e de limitatio que nos interessam aqui, depende de vários tipos documentais: fontes literárias, nas quais há descrições de ritos, nomes de magistrados e de sacerdotes, registros de cerimônias, que se unem a uma literatura técnica, como os textos reunidos no Corpus Agrimensorum Romanum que, mesmo tendo sido compilados no período flaviano, remontam à República ${ }^{5}$. Do mesmo modo, chegaram até nós inscrições epigráficas diversas, nas quais entrevemos, por exemplo, leis de fundação de colônias, além de imagens que trazem representações de ritos de fundação e objetos do registro arqueológico, como os cippi, que demarcavam fronteiras e territórios. Magistrados definiam fronteiras (termini) e organizavam territórios em situações específicas (kardi, decumani, centuriae, limites, rigores), além de orientarem seu uso (lex data/lex dicta). Tal organização envolvia e remetia a rituais religiosos. Na cena ritual, o oficiante dividia (fisicamente) a terra e definia (verbalmente) seu uso, em ações e formulae análogas a algumas práticas centrais da religio romana, especialmente a ratio templi.

À guisa de trazer alguns elementos para o debate sobre os limites romanos, apresentaremos uma breve abordagem dos ritos de fundação de cidades, destacando procedimentos atribuídos às fundações das coloniae Latinae no século IV a.C., comparando-os a ações rituais do colégio dos áugures cujas tarefas, a nosso ver, envolviam a definição e a manutenção das fronteiras entre o divino e o humano, o "interior" e o "exterior", protegendo a urbs fundada (condita, lit. "reunida"), buscando uma via de acesso à compreensão dos fundamentos da lógica espacial romana.

5 Diversos textos antigos sobre o tema, especialmente do período imperial, foram estudados, traduzidos e comentados por especialistas, permitindo um acesso mais fácil a textos técnicos em latim, como as publicações a cargo de François Favory, Antoine Gonzales, Jean-Yves Guillaumin e Philippe Robin para a Revue Archéologique du Centre de la France, em boa parte disponíveis no portal Persée: www.persee.fr 


\section{Magistrados, religião e ação ritual}

Os magistrados romanos agiam em contextos definidos que limitavam o tempo, o lugar e a forma de suas atividades e, num mundo no qual a oralidade era dominante, podemos perceber a importância dos rituais - e de sua correta execução - para os procedimentos administrativos romanos e, mesmo no período que denominamos "República tardia", Roma não contava com um número extenso de pessoas envolvidas no aparato governamental. Para a República tardia, por exemplo, menos de 50 postos regulares são detectados. Tais postos eram, decerto, complementados por funções ad hoc e magistraturas excepcionais que, assim como as magistraturas maiores e menores regulares, eram limitadas no tempo e nas ações, além de serem, quase todas, colegiadas. Nenhuma delas agia em total independência: o Senado acompanhava e intervinha sistematicamente nas ações governamentais, além de os colégios sacerdotais - especialmente pontifices e augures -, também com diferentes áreas de atividades e atribuições, permearem as magistraturas e o Senado, agindo conjuntamente. Some-se o fato de haver uma nítida identificação entre liderança política e liderança religiosa, o que é expresso por Cícero, no século I a.C.:

Entre as muitas instituições, membros do colégio dos pontífices, criadas e estabelecidas por nossos antepassados sob a inspiração dos deuses, nada é mais sábio do que sua decisão de atribuir aos mesmos homens o culto dos deuses e o cuidado dos interesses do Estado; o resultado é que os mais ilustres cidadãos podem assegurar a manutenção da religião pela administração apropriada do Estado e a manutenção do Estado pela cuidadosa interpretação da religião (Cícero, De domo sua, 1).

Magistrados, sacerdotes e senadores, muitas vezes os mesmos indivíduos, eram as figuras centrais da vida pública romana ${ }^{6}$ e esta afirmação pode ser estendida, sem riscos de generalização abusiva, a todo o período republicano romano. Essas figuras controlavam as fronteiras entre os âm-

6 SCHEID, J. Le prêtre et le magistrat. Réflexions sur les sacerdoces et le droit public à la fin de la République. In: NICOLET, C. (Org.). Des ordres à Rome. Paris: Publications de la Sorbonne, 13, 1984 , p. $243-81$. 
bitos humano e divino, entre as esferas pública e privada, entre o exterior e o interior, etc. A religião e a lei pública definiam classes de atores (e, por conseguinte, de espectadores), cada qual com responsabilidades, poderes e procedimentos apropriados ${ }^{7}$. Em tempos e situações diferentes, um mesmo indivíduo desempenhava o papel de magistrado, de senador ou de sacerdote, além de também agir como priuatus, e muitas dificuldades da historiografia moderna advêm do descuido na compreensão das interações entre esses papéis. A ação religiosa e governamental propriamente dita concentrava-se na figura do magistrado, o que implicava todo um programa religioso para as magistraturas, incluindo a realização de sacrifícios, jogos, procissões etc., em tempos fixos ou em situações excepcionais, e precisamos estar atentos para o fato de que ações governamentais que na modernidade são consideradas "seculares" (como os julgamentos em tribunais, a presidência de assembleias populares e as ações de guerra) incluíam elementos religiosos, como, e.g., os ritos divinatórios que as precediam (cf. Cícero, N.D., 2,4,11; Diu. 1.17.33; Varrão. L.L. 6, 90-92). Para o nosso modo de ver as coisas, as várias esferas do governo parecem entremescladas na Roma republicana.

As ações governamentais na República romana nos surgem, portanto, centradas e expressas em ritos religiosos e/ou em cerimoniais públicos - e a distinção entre essas categorias é altamente discutível - e os magistrados, atores principais desses ritos, eram seus principais oficiantes, o que pode parecer surpreendente, posto que Roma é tradicionalmente considerada uma civilização centrada na lei. Mas é preciso lembrar que somente a lei civil romana foi objeto de codificação e, segundo A. Magdelain, apenas no que concernia a situações nas quais o cidadão particular deveria utilizar a linguagem da lei, geralmente restrita ao magistrado e ao sacerdote; o ius publicum e o ius sacrum (parte do primeiro) nunca foram submetidos a codificação ${ }^{8}$. Assim, os ritos e cerimônias eram ocasiões nas quais se organizava o corpo cívico, se instituía e consolidava a liderança, se comunicavam as demandas e decisões e se movia o corpo cívico às ações

$7 \quad$ Ulpiano (Dig. 1.1.1.2), e.g., divide a lei pública em leis concernentes aos sacerdotes, aos magistrados e às assembleias, seguindo uma divisão apresentada por Cícero (Rep $1.25 .39 ; 1.27 .43 ; 1.32 .48)$ definindo o termo res publica como a propriedade do populus e tudo o que concernia a ela, e tratando ( Leg. 2.27.69 ss.) as leis referentes aos magistrados após as leis relativas aos sacerdócios e aos sacra.

8 Cf. MAGDELAIN, A. Ius imperium auctoritas. Études de droit romain. Rome: École Française de Rome, 1990. Ver também SCHEID, J. Oral Tradition, Written Tradition. The Formation of Sacred Law in Rome. In: ANDO, C.; RÜPKE, J. Religion and Law in Classical and Christian Rome. München: Franz Steiner Verlag, 2006. p. 14-33. 
desejadas, ao passo que orientavam e limitavam o tempo, o lugar e a forma das atividades dos representantes e líderes do corpo cívico, com padrões, procedimentos e regras bem definidos.

A partir do século IV a.C., a expansão territorial romana paulatinamente estendeu-se para além do Lácio, em todas as direções. A administração da res publica e de seu imperium estava localizada, essencialmente, na própria urbs; na Roma médio e tardo-republicana, magistrados maiores e menores realizavam a maior parte de suas funções em espaços públicos, sacralizados pelas tradições e pelas práticas religiosas, conseguindo manter um vasto território sobre o qual agiam diretamente num número limitado de ações e casos, derivando-se um grau considerável de autonomia local para os povos do imperium. Os magistrados romanos fora de Roma parecem ter sido responsáveis, principalmente, pela condução da guerra, e é possível que estivessem presentes apenas nos locais em guerra ou sob a ameaça de guerra. Em suma, magistrados romanos agiam diretamente nos locais conquistados quando a ordem imposta por Roma parecia ameaçada, ou quando tarefas específicas, como a fundação de coloniae $e^{9}$ ou de terras uiritim $^{10}$, requeriam sua presença para a condução dos ritos, por um período limitado de tempo. Extra Itália, a presença regular de magistrados romanos foi institucionalizada especialmente após a formação das primeiras províncias.

O desenvolvimento de um sistema hierarquizado de estatutos legais de aliados e povos conquistados em relação a Roma é um processo que ainda demanda estudos, sendo bastante obscuro até o momento. Temos como hipótese ativa a ideia de que os processos pelos quais Roma assegurou seu domínio sobre seus vizinhos no Lácio e na Itália central, estendendo as

9 Em linhas gerais, podemos dizer que a Guerra Latina (circa 340 - 338 a.C) trouxe grandes mudanças na relação entre Roma e seus aliados e inimigos vizinhos. Algumas comunidades foram incorporadas a Roma e seus territórios tornaram-se parte integrante do território romano, com seus cidadãos admitidos à cidadania romana, enquanto outras não obtiveram o direito de voto em Roma. A certas cidades foi reconhecido o status de municipium, mantendo suas formas de governo, de sacerdócio, leis, costumes, etc. Outras se mantiveram como aliadas independentes, algumas com status de cidadania latina, ao passo que Roma assegurava o controle sobre essa rede de entidades subordinadas criando novos assentamentos para proteger pontos cruciais nas fronteiras e linhas principais de comunicação, servindo como postos avançados contra comunidades inimigas ou potencialmente hostis, as coloniae, cujos habitantes recebiam ora a cidadania romana, ora a latina e eram organizadas segundo modelos da $u r b s$. Uma hipótese recente - que demanda maiores estudos - foi apresentada por D. Gargola (ver nota 4) sobre o status superior da cidadania latina sobre a romana nesta rede organizacional médio-republicana.

10 Em terras mais próximas do ager Romanus, e protegidas por coloniae, os romanos destinavam terras confiscadas a indivíduos organizados comunalmente de modo dependente de Roma, o que foi chamado uiritim. Colônias e assentamentos viritanos não foram criados fora da Itália antes do final do século II a.C. 
fronteiras de seu próprio território e tornando suas conquistas mais seguras, podem servir como padrões para a organização de futuras conquistas, nas quais as relações formalizadas, as categorias legais e os procedimentos ritualizados tornavam-se cada vez mais abstratos, mais padronizados e mais elaborados, ocupando um lugar central na visão romana da ordem cívica e imperial. Nesse longo processo, a religio publica, que se alterava e se constituía também de acordo com as mudanças políticas e sociais, forneceu elementos para a formação, consolidação e canalização do imperium, a partir de processos que podemos definir como ritualização, abstração e sistematização, subsumidos por J. Rüpke no conceito de racionalização ${ }^{11}$.

\section{Inauguratio $e$ a ratio templi}

O colégio dos áugures, segundo Cícero, foi criado por Rômulo (Rep. 2.16), enquanto Tito Lívio atribui sua criação a Numa $(4,4,2)$; contudo, declara que Numa fora inaugurado quando chegou a Roma e, em seu relato da fundação, apresenta Rômulo e Remo traçando seus espaços augurais, respectivamente, no Palatino e no Aventino (1.18.6-10; 1.6.4). Cícero afirma que os gêmeos fundadores eram áugures (Diu. 1.107-8) e, segundo Plutarco, Rômulo teria reunido especialistas etruscos para fazer com que Roma fosse fundada de acordo com os textos e as práticas sagradas (Plut. Rom. 11.1) e temos como pressuposto que esses autores seguiam uma opinião corrente de que a $u r b s$ fora fundada segundo os rituais etruscos (cf. Varrão, L. L. 5. 143; Festo. 358L, s.v. rituales $)^{12}$.

11 Jörg Rüpke retoma e redefine o conceito weberiano de racionalização, abstraindo das assunções de Weber no campo das religiões, hoje discutíveis, considerando-o como um modelo interpretativo útil para a compreensão do processo de sistematização das práticas religiosas e sua transformação em discursos especializados, regras e loci institucionais. Para Rüpke, racionalização implica elaboração, codificação e sistematização da prática expressa em performances, guiando a conduta - designadamente da elite governamental - e as necessárias e eventuais inovações: RÜPKE, J. Religion in Republican Rome. Rationalization and Ritual Change. Philadelphia: University of Pennsylvania Press, 2012. p. 82-110.

12 Cícero, membro do colégio dos áugures, declara que a tarefa principal dos áugures era tomar os auspicia (Cícero. ND, 1.112), mas que, para tal, outras cerimônias eram exigidas, bem como diz que os áugures realizavam algumas ações por si mesmos e colaboravam em outras realizadas por magistrados e pelo pontifex maximus. O colégio, então, tanto agia por iniciativa própria quanto sob demanda dos magistrados, do pontifex maximus ou do Senado. 
Esse colégio era um dos mais importantes colégios sacerdotais republicanos e tinha como tarefa, especialmente, a definição e manutenção das fronteiras entre o divino e o humano; se endereçava às divindades nos eixos dessas fronteiras, mediante questões que eram respondidas por sinais que precisavam ser decifrados (decreta et responsa), e o sistema augural ocupava um lugar destacado no governo republicano. Em outras palavras, esse colégio, vinculado a Júpiter e às ações dos magistrados nas quais pessoas e lugares eram inaugurados, tinha um papel central na categorização e na definição do espaço para fins políticos e religiosos ${ }^{13}$. Comecemos, então, pela observação dos rituais dos áugures que se concentravam na inauguratio, em particular do pomerium, separando a zona augural da urbs de outras zonas ${ }^{14}$. Tais zonas eram definidas, em princípio, por gestos e palavras rituais ${ }^{15}$. Os áugures também preservavam ritualmente as linhas que separavam tipos de terras, segundo Cícero, "liberando e desobstruindo a cidade, os campos e os templa" (Leg. 2.8.21).

Essa tarefa implicava duas atividades correlatas: a effatio e a liberatio. A effatio estabelecia as linhas que separavam o espaço augural das terras circundantes, criando os fines ("limites"). A liberatio, por sua vez, significava remover influências e interferências humanas ou divinas indesejadas no ager effatus. A effatio e a liberatio resultavam no processo de inauguratio, ou seja, a criação de um lugar ritualmente definido, um locus inauguratus ${ }^{16}$, e a lógica dentro/fora é fundamental para a classificação augural. Na Roma republicana, as inaugurationes ocorriam entre a meia-noite e a aurora e o silêncio era necessário, bem como a boa visibilidade do auguraculum. $\mathrm{O}$ áugure oficiante, capite uelato, levava o lituus em sua mão e precisava ver o lugar que inaugurava, pronunciando as palavras rituais ${ }^{17}$.

13 LINDERSKI, J. The augural law. ANRW II. 16.3, 1986. 2146-312.

14 O pomerium era um tipo particular de templum. Segundo a tradição literária, o primeiro pomerium de Roma situava-se aos pés do Palatino e as pesquisas arqueológicas de A. Carandini, nos anos 1990, abriram a possibilidade de que um pomerium palatino existisse no século VIII a.C.: cf. CARANDINI, A. Palatino e sacra via I. Prima delle mura, l'età delle mura, l'età case arcaiche. Roma: Istituto Poligrafo, 1995.

15 Os procedimentos augurais provavelmente não são criações romanas, mas o colégio propriamente dito, com seu auguraculum no Arx é, possivelmente, uma das criações institucionais da urbs.

16 Cf. Festo, s.v. liberata, 128L. Ressaltando o caráter especial do locus inauguratus, outra série de ritos promovia a exauguratio; o relato literário mais famoso deste tipo é o da recusa do deus Terminus de sair do sítio do templo de Júpiter Capitolino, cf. BELTRÃO, C. Terminalia: fronteiras e espaço sagrado. Phoînix, v. 17, p. 82-99, 2011.

17 As principais fontes textuais para o rito são o relato de T. Lívio sobre Numa em 1.18.6-10 e Varrão, L.L. 7.8-10, que apresenta a formula augural no Arx para a criação, delimitação e divisão de um templum. 
Podemos identificar três ações básicas no ritual de definição do espaço: 1) a identificação verbal do espaço no momento de sua criação; 2) a indicação de seus limites por meio de gestos; 3) o estabelecimento de marcos territoriais permanentes. O locus classicus dessas ações é o relato de Tito Lívio sobre Numa e a criação do templum:

Conduzido então à cidadela pelo áugure, para a qual depois esse sacerdócio tornou-se público e permanente, Numa, voltado para o sul, sentou-se numa pedra. O áugure, com a cabeça coberta e segurando na mão direita um bastão recurvado e sem nós, chamado lituus, ocupou o lugar à sua esquerda. Em seguida, sendo os deuses invocados, o áugure, mantendo o olhar na direção da cidade e do campo, depois que determinou no céu uma linha do nascente ao poente, afirmou que à direita estavam as regiões do sul e à esquerda as do norte. Mentalmente, fixou o ponto visível mais distante à sua frente. O áugure, então, transferindo o bastão para a mão esquerda e colocando a mão direita sobre a cabeça de Numa, pronunciou estas palavras: "Se está de acordo com o direito divino este Numa Pompílio, cuja cabeça eu seguro, ser rei de Roma, ó Pai Júpiter, eu suplico que nos mostres sinais seguros entre os limites que tracei". Em seguida arrolou aos auspícios esperados. Tendo sido presenciados os auspícios, Numa, declarado rei, desceu do templo (T. Lívio, 1.18,6-10) ${ }^{18}$.

O sacerdote, tomando seu lituus, determinava as regiones (linhas) e separava a área do templo, enquanto pronunciava uma fórmula (legum dictio), pedindo a Júpiter que enviasse signa certa nesses limites ${ }^{19}$. A lex dicta governava o uso do templum, temporário ou permanente, de um modo análogo àquele pelo qual a lex pronunciada no momento da dedicação regia um aedes.

18 Inde ab augure, cuideinde honoris ergo publicum id perpetumm que sacerdotium fuit, deductus in arcem, in lapide ad meridiem uersus consedit. Augur ad laeuameius capite uelato sedem cepit, dextra manu bacullum sine nodo aduncum tenens, quem lituum appellarunt. Inde ubi prospectu in uerbe magrumque capto deos precatus regiones ab oriente ad occasum determinauit, dextras ad meridiem partes, laeuas ad septentrionem esse dixit; signum contra quo longissime conspectum oculi ferebant animo finiuit. Tum, lituo in laeuam manum translato, dextra in caput Numae imposita, precatus ita est: "Iuppiter pater, si est faz hunc Numam Pompilium cuius ego caput teneo regem Romae esse, uti tu signa certa adclarassis intereos fines quosfeci". Tum peregituerbis auspicia quaem ittiuellet. Quibus missis, declaratus rex Numa de templo descendit. (T. Lívio, 1.18,6-10; Tradução de Monica Costa Vitorino. Tito Lívio. História de Roma desde a fundação da cidade. L. I - A Monarquia. Ed. Bilíngue. Belo Horizonte: Crisálida, 2008).

19 Cf. também: Cícero. Diu. 1.17.31; Varrão, L.L. 7,9. 
Um lugar inaugurado era marcado com uma stella ou uma crux de bronze (cf. Festo, 476L) e, em Roma, tal lugar deveria ser visível do auguraculum no Arx e era claramente delimitado por marcos (termini ou cippi). Assim, árvores eram derrubadas, bem como construções demolidas, caso obstruíssem a visão dos loci inaugurati. Era nefasto cobrir um terminus, bem como termini quebrados ou removidos indevidamente tinham de ser restabelecidos - o que nos remete ao relato da recusa de Terminus de sair do Capitólio, permanecendo na cella de Júpiter, que manteve uma abertura no teto ${ }^{20}$. Publici termini eram sancti ${ }^{21}$, ou seja, protegidos pela lei augural, e a preservação desses marcos públicos era uma das mais importantes tarefas dos áugures.

Em locais inaugurados, ritos públicos eram iniciados pela tomada dos auspicia e signa ex auibus demonstravam a concordância de Júpiter. Esses signa eram solicitados (impetratiua), não espontâneos, ou seja, ocorriam por meio do diálogo formal de um áugure com Júpiter, chamado legum dicto, ou nuncupatio, pelo qual os signa se tornavam seguros (certa), não ambíguos $^{22}$. A forma mais comum de inauguratio era a instauração de um espaço retangular - o templum - que, quando submetido a outros ritos de consecratio e dedicatio, tornava-se o local de um aedes, uma ara, etc. ${ }^{23}$.

Os templa eram lugares privilegiados para o funcionamento das magistraturas e dos sacerdócios. Neles, auspicia eram tomados, magistrados presidiam assembleias e tribunais, censores iniciavam o lustrum, promessas eram feitas, bem como dedicações, partilhas e senatus consulta só eram válidos após serem depositados num aedes de templum (Varrão, L.L. 6.86-87, 91). Fora de Roma, acampamentos militares tinham espaços análogos ao templum (Políbio, Hist. 6. 27-31; T. Lívio. 41. 18,6-10; Tácito,

20 BELTRÃO, C. Terminalia: fronteiras e espaço sagrado. Phoînix, v. 17, p. 82-99, 2011

21 Sanctus é um conceito exclusivo da lei augural. Rigorosamente falando, um aedes ou uma ara consagrados eram sacrae, enquanto um templum era res sanctae. Temos um bom exemplo dessa distinção no aedes Vestae ("Templo" de Vesta). Este edifício era consagrado, era res sacrae, mas não era um templum. O contrário pode ser visto em relação à Cúria Hostília e ao próprio pomerium; ambos eram templa, mas não eram consagrados. A inauguratio cria a res sancta, enquanto a consecratio, a res sacra.

22 Os áugures provavelmente interpretavam uma grande variedade de signa divinos, dividindo-os em propícios e não propícios.

23 Ressalte-se que, no caso da consecratio e da dedicatio, outros atores religiosos entravam em cena: a consagração e a dedicação de um templum a uma divindade particular, sob a forma, e.g., de um aedes, era feita por um magistrado acompanhado por um pontífice, também seguindo regras e procedimentos rígidos; cf. Cícero. De domo sua. 52,133; T. Lívio. 1.10,5-7; 2. 8,6,8. 
Ann. 15,30$)^{24}$ e ressaltamos que não apenas lugares, mas também pessoas eram inauguradas. Como magistrados e pontífices tomavam os auspicia em benefício da res publica, eram também inaugurados pelos áugures. Inaugurar algo ou alguém era, em suma, alterar ou elevar radicalmente seu status, tornando-o sanctus.

Esse sistema, segundo Rasmussen e Rasmussen,

[...] emerge como uma disciplina científica fundada em sua própria dimensão temporal e espacial, caracterizada por um profissionalismo estrito, aplicando uma metodologia especial destinada a: 1) observar vários fenômenos portentosos; 2) classificar essas informações; 3 ) interpretá-las; 4) permitir análises comparativas e 5) realizar investigações diacrônicas. Todo o sistema é fundado num conjunto de observações pontuais e as análises empíricas eram levadas a cabo por especialistas religiosos que interpretavam o material, em sua dimensão espaço-temporal, com o objetivo de compreender o mundo e estabelecer contextos sagrados e profanos. ${ }^{25}$

A auspicação era um ritual religioso $e$ político, no pleno sentido do termo. O colégio dos áugures mantinha Júpiter sob controle ${ }^{26}$ ao dividir simbolicamente o céu e a terra, criando um templum de quatro partes, com as grandes linhas, o kardo e o decumanus, que surgem também na ação dos agrimensores e cujos princípios de divisão espacial são semelhantes aos da ratio templi.

Semelhantes, mas não idênticos. É preciso, então, comparar a inauguratio do templum e o ritual de fundação, buscando suas analogias e suas diferenças.

24 Ver também: WALBANK, F. W. A Historical Commentary on Polybius. Oxford: Oxford University Press, 1999. p. 709-723.

25 RASMUSSEN, A. H.; RASMUSSEN, S. W. (Ed.). Religion and Society: Rituals, Resources and Identity in the Ancient Graeco-Roman World. The BOMOS Conference 2003-2005. Analecta Romana Instituti Danici. Rome: Quasar, 2008. p. 207.

26 SCHEID, J. Numa et Júpiter, ou les dieux citoyens de Rome. Archives des Sciences Sociales des Religions, v. 59, n. 1, p. 41-53, 1985. 


\section{Marcos territoriais e limitatio}

Marcos territoriais visíveis eram - e são - uma necessidade. Cippi ou termini e limites (fronteiras) eram recomendados, ordenados e esperados em várias circunstâncias, e a tradição representava Rômulo estabelecendo o pomerium de Roma, com seus termini.

Catão $(A g r$.) e Varrão (R. 1.14-15) orientavam aos proprietários privados que plantassem árvores e outros expedientes para indicar os limites de suas propriedades. Os marcos físicos, contudo, garantidos e protegidos por Terminus, definindo as propriedades, eram mais do que uma necessidade de uso particular, recebendo destaque nos Fasti, L. II, de Ovídio. A defesa desses marcos contra os efeitos do tempo e da atividade humana era tema de grande relevância. Dionísio de Halicarnasso (2.74) afirma que Numa recomendara que priuati instaurassem marcos de fronteira com ritos apropriados em honra de Júpiter Término, bem como que os limites da terra pública fossem estabelecidos do mesmo modo. A agressão a esses marcos - terminus motus ou crimen termini moti - era uma das mais antigas violações sancionadas da lei romana e sua origem foi atribuída a Numa (cf. Dion Hal. 2.74; Plut. Num. 16, Quaest. Rom. 15; Festus, 505L).

Observemos, em linhas gerais, a complexa classificação das terras e territórios em relação às regras, rituais, atores e atividades neles permitidos. Há de considerar, em primeiro lugar, as distinções entre o território de Roma propriamente dito e outros territórios. Seguiremos, para tal, a classificação exposta por Varrão (L. L. 5.33) ${ }^{27}$.

A classificação das terras era um item da lei augural e Varrão argumenta que os áugures reconheciam cinco tipos de terras: ager Romanus, ager Gabinus, ager peregrinus, ager hosticus e ager incertus ${ }^{28}$. O ager Romanus teria um sentido augural pleno ${ }^{29}$. A distinção entre ager Romanus e ager

27 No que tange à documentação textual, outros textos remetem ao tema da classificação das terras. Citamos, e.g., De Domo Sua, de Cícero, que vincula a aplicação da "lei romana" ao ager Romanus ao tratar do direito de exílio, baseado na prática aparentemente arcaica do postliminium, que permitia ao cidadão reclamar seu status e suas propriedades na urbs após seu retorno, e uma passagem da correspondência de Plínio, o Jovem (Ep. 10.50), na qual as fronteiras do ager Romanus surgem marcando os limites das práticas religiosas romanas.

28 Não foi possível delimitar as datas de origem desse sistema de classificação; Varrão o apresenta como uma antiguidade.

29 É possível que esse sentido augural pleno se refletisse nos rituais arcaicos de fronteira, como a Terminalia. Pelo relato de T. Lívio, podemos compreender algo sobre as exaugurationes e sobre o status legal dos termini. 
Gabinus pode remontar a fins do século VI a.C., quando Gabius tornou-se aliada de Roma $^{30}$. Para Christian Kvium, os três primeiros tipos eram território romano; o hosticus era terra "estrangeira", potencialmente hostil, e a quinta categoria, ager incertus, é de mais difícil definição $0^{31}$. Segundo Varrão, cada uma dessas cinco categorias tinha suas próprias formas de auspicia - e.g., na urbs, os magistrados tomavam os auspicia urbana - e as linhas de separação (fines) entre os diferentes agri tinham um significado ritual.

No interior da urbs, uma distinção espacial parece ter sido importante: a urbs e o suburbium, tendo o pomerium como demarcação que estabelecia a distinção e o relacionamento das esferas das domi e das militia, central na determinação dos poderes e da atuação dos magistrados e dos direitos dos cidadãos. O ager effatus não era definido segundo essas categorias, podendo ser compreendido, grosso modo, como a área exterior ao pomerium e, para Rüpke, o ager Romanus incluía a urbs e o ager effatus, com a linha do pomerium interconectando - mais que separando - essas duas áreas ${ }^{32}$. E um dos papéis - talvez o principal - dos áugures era o de proteger a urbs, símbolo do imperium romanum, i.e., sua expressão espacial "fundada" (literalmente "reunida") no pomerium.

De fato, vários atores tinham o direito de definir limites em diferentes ocasiões: proprietários privados marcavam as fronteiras de suas próprias terras e magistrados o faziam em relação a terras públicas, seja para fins religiosos ou não. Nos séculos III e II a.C., magistrados específicos - os finitores - eram encarregados dessas tarefas e, a partir de fins do século II a.C., à época dos irmãos Graco, plebiscitos instituíam comissões especiais - tres uiri coloniae deducendae - para demarcar o território de colônias e assignar propriedades privadas e colégios - os decemuiri agro dando - para as ações equivalentes em territórios viritanos. No mesmo período, censores, cônsules e pretores tinham o ius publicum priuatorum locorum para a definição dos espaços

30 Para Catalano, contra Mommsen, que defendia que a categoria Gabinus incluía todos os territórios latinos incorporados a Roma, apenas o território de Gabius foi classificado em separado, enquanto os territórios dos demais povos latinos eram ager peregrinus, cf. CATALANO, P. Aspetti spaziali del sistema giuridico-religioso romano. Mundus, templum, urbs, ager, Latium, Italia. $A N R W$ II, v. 16, n. 1, p. 440-553, 1978 .

31 KVIUM, Ch. Inauguration and Foundation. An Essay on Roman Ritual Classification and Continuity. In: RICHARDSON, J. H.; SANTANGELO, F. Priests and State in the Roman World. München: Franz Steiner Verlag, 2011. p. 63-90, p. 65.

32 RÜPKE, J. Domi militiae. Die religiöse Konstruktion des Krieges in Rom. Stuttgart: Franz Steiner Verlag, 1990. p. 31-35. 
públicos, assim como esses magistrados e os duumuiri aedibus dedicandae definiam templos, altares e os dedicavam aos deuses, até a lex Papiria (174 ou 154 a.C.) que limitou o número de magistrados com poder para tal.

Assim, terras eram destinadas a usos específicos, exigindo que magistrados definissem a área em questão, e as regras que a governariam (leges datae ou leges dictae), estabelecidas pela autoridade instituída e reconhecida como tal. Fundadores de colônias, no momento da criação do assentamento, proclamavam pela lei e pela religião, a lex do assentamento e a área sobre a qual esta se aplicava, muitas vezes identificando suas fronteiras em detalhes ${ }^{33}$.

Podemos dizer que o controle dos marcos territoriais simbolizava o controle do território e, consequentemente, a ordem cívica e religiosa. Um exemplo provém de T. Lívio, sobre a deditio da Collatia:

Tenho a informação de que os colatinos se renderam e que foi esta a fórmula da rendição. O rei perguntou: "Por acaso vós sois os embaixadores e os porta-vozes enviados pelo povo colatino para que vós e o povo colatino vos rendêsseis?"; "Somos"; "Por acaso o povo colatino está em seu pleno poder de deliberação?"; "Sim"; "Por acaso vós vos entregais e também o povo colatino, a cidade, os campos, a água, os limites, os templos, os utensílios e todas as coisas sagradas e profanas para meu poder e do povo romano?"; "Entregamos"; "E eu recebo". (T. Lívio. 1.38-1-2; grifo nosso $)^{34}$.

A conquista romana, obviamente, agiu sobre o território de povos distintos e sobre a paisagem, a partir de uma rede de estradas, limites, etc.,

33 Há diversos exemplos em inscrições epigráficas, como em ILS 112: [...] his legibus hisque regionibus dabo dedicaboque, quas his hodie palam dixero ("Eu darei e dedicarei por essas leis e essas regiones que eu direi aqui publicamente"; tradução da autora). Vemos, pelo exemplo, uma característica dessas inscrições epigráficas: destacam o papel do magistrado e suas ações, sua autorização e, por fim, o status da terra. Os procedimentos rituais recebem mais ênfase do que os resultados. Ver também ILS 24; 9376.

34 Deditosque Collatinos ita accipio eamque deditionis formulam esse: rex interrogauit: "Estisnes uos legatioratores quem issi a populo Collatino ut uos populumque Collatinum dederetis?" "Sumus". - “Estne populus Collatinus in sua potestate?" - "Est." - "Deditisne uos populumque Collatinum, urbem, agros, aquam, terminos, delubra, utensilia, diuina humanaque omnis, in meam populique Romani dicionem?" - "Dedimus". - “At ego recipio". (T. Lívio. 1.38-1-2; Tradução de Monica Costa Vitorino. Tito Lívio. História de Roma desde a fundação da cidade. L. I - A Monarquia. Ed. Bilíngue. Belo Horizonte: Crisálida, 2008). 
num processo que mudava o padrão de uso dessas terras e estabelecia novas formas. O ritual de fundação de colônias, que nos interessa aqui especificamente, ocorria de acordo com a inauguratio de um pomerium e era, entre os séculos IV e II a.C., realizado por um dos três legados senatoriais, instituídos por uma lex coloniae deducendae. Os tres uiri coloniae deducendae eram magistraturas extraordinárias cum imperium que monitoravam os trabalhos dos agrimensores antes da construção propriamente dita, bem como eram os responsáveis pelos ritos de inauguração do pomerium. Para Mario Torelli, seu modelo eram os "companheiros-guerreiros" (suodales) de Poplios Valesios, que fizeram para si mesmos o monumento do Lapis Satricanus (ca. 500 a.C.) e desempenharam um papel central na colonização do Lácio no século V a.C., que, aos poucos, foi organizada institucionalmente ${ }^{35}$.

Na divisão das terras, conhece-se o sistema de Kardi, decumani, centuriae, limites ("faixas"), rigores ("linhas"), já utilizados em assentamentos viritanos, como Privernium e o ager Falernus (340 a.C.), e nas primeiras colônias: Cales (334), Luceria (314), Alba Fucens (303), Cosa (273), Ariminium (268), Cremona (219) e, depois, nas colônias de Bononia (189), Luna (177), Mutina (183) e Parma (183), criando um sistema bastante regular de divisão de terras e sua distribuição, e esse sistema tinha claras analogias com os rituais augurais. Magistrados romanos realizavam a terminatio para definir os limites externos de uma seção de terra e estavam também autorizados a dividir tal terra em várias seções internas (limitatio), visando à sua distribuição, assignação ou venda entre colonos. Segundo Catalano, a limitatio seguia procedimentos que podem ser datados do século IV a.C. (1978), tratando de dividir a terra paralelamente aos decumani em faixas estreitas (limites) e, então, estabelecendo linhas (rigores) transversais, subdividindo-os e, com isso, criando módulos retangulares homogêneos, que podiam também ser subdivididos, como vemos no modelo da página seguinte.

O registro arqueológico permite detectar uma regularidade no sistema de fundação e divisão de terras, a partir de decumani - teoricamente seguindo a linha leste-oeste - e kardi - tendendo ao curso norte-sul - com interseções em ângulos retos, os limites, divididos em rigores. Dois eixos ortogonais principais eram o decumanus maximus e o Kardo maximus, cuja

35 TORELLI, M. Religious Aspects of Early Roman Colonization. In: Tota Italia. Essays in the Cultural Formation of Roman Italy. Oxford: Oxford University Press, 1999. p. 14-42. 


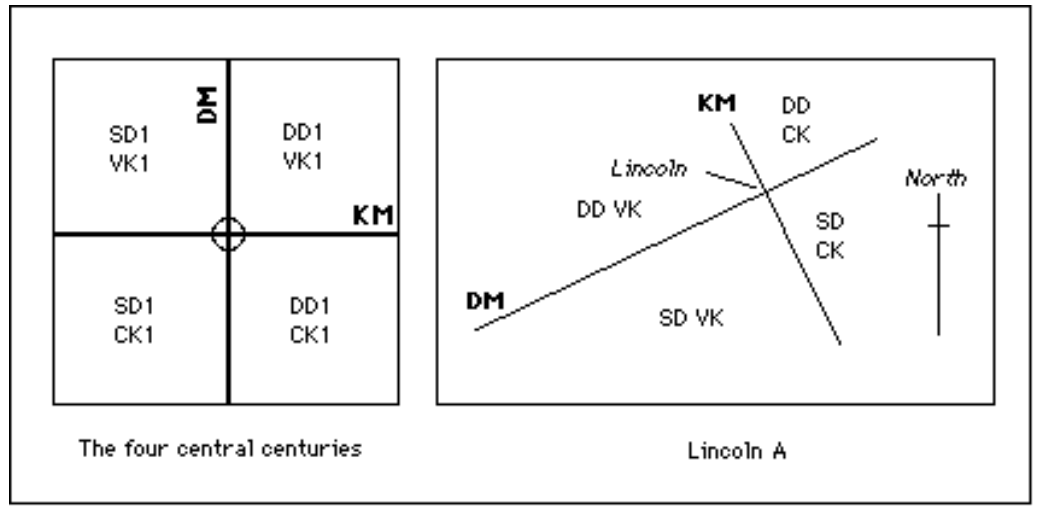

FIGURA 1 - ESQUEMA DO SISTEMA ROMANO DE CENTURIAÇÃO. (FONTE: http://www.uea.ac.uk/ jwmp/glossary.html)

interseção formava o ponto central do território (ao menos conceitualmente). Quando possível, os limites eram paralelos e separados à distância de 20 actus $(708 \mathrm{~m})$ e os quarteirões formados por tais faixas contavam 200 iugera, sendo conhecidos como centuriae. Cada centúria podia ser subdividida em rigores, criando pequenos lotes de terra (neste caso, os padrões não são regulares). As centúrias ficavam à direita (dextra) ou à esquerda (sinistra) do Kardus maximus e abaixo (kitra) ou acima (ultra) do decumanus maximus, facilitando a localização das unidades, com a numeração iniciando-se na interseção do Kardo maximus com o decumanus maximus. Em ILS 24, por exemplo, há uma inscrição de um marco territorial de Caio Graco; o local era a interseção do $11 .^{\circ}$ limes kitra do decumanus com o $1 .^{\circ}$ da sinistra do Kardo.

A observação das formas de fundação e demarcação de terras permite supor que o sistema era baseado no ritual religioso. É possível, dada a indissociabilidade entre religião e política, que os romanos tenham usado antigos sistemas de orientação religiosa, que estão na base da auspicatio, como forma de orientação e divisão do espaço em geral. Associados aos templa por analogia, a ação de magistrados fundadores de colônias criava espaços definidos, sacralizando-os não somente pelos rituais realizados, mas pelo próprio sistema de marcação e orientação das linhas no solo. 
De acordo com Servius, o finitor de uma colônia apresentava-se capite uelato como um áugure e togado de modo militar solene, cinctus Gabinus, o que denota que o ritual da fundação recaía na interseção das esferas religiosa e militar (miliae $=$ fora do pomerium) e todos os textos supérstites são unânimes em citar um boi (no exterior e à direita) e uma vaca (no interior e à esquerda) no rito de fundação para o traçado do pomerium, o que implica um sentido anti-horário na marcação do solo ${ }^{36}$.

Segundo Kvium:

Rigorosa e semanticamente falando, os procedimentos rituais se referem à fundação das 33 coloniae Latinae na Itália entre 334 e 218 a.C., todas erguidas a fundamento. Seu propósito era, sem dúvida, militar, defensivo e eram reconhecidas por Roma como ciuitates, fosse qual fosse sua composição étnica. Talvez o conservadorismo ritual tenha mantido os augúrios e a marcação na terra de fundações posteriores, que não eram mais denominadas urbes; essas tinham diferentes propósitos e, muitas vezes, eram sobrepostas a comunidades urbanas preexistentes. $\mathrm{E}$, mais importante, não eram reconhecidas como novas nationes e seus colonos retinham sua cidadania romana, ou a recebiam ${ }^{37}$.

Mais do que um "conservadorismo ritual”, que pode levar à (falsa) crença de que a religio romana era um corpo de práticas e conhecimentos cristalizados e repetidos à exaustão, consideramos que os rituais de fundação e seu desenvolvimento no tempo e no espaço refletem a centralidade das práticas rituais romanas na urbs e seu papel no processo de racionalização de ações governamentais que estão na base da criação e do sucesso do sistema imperial romano. Esse processo, que possivelmente visava à solução de problemas ad hoc, estava calcado no sistema de valores e na visão de mundo romana - ou de sua elite - institucionalizando ações e conhecimentos técnicos e administrativos, constantemente abstraídos, reelaborados e ressignificados ao longo dos tempos.

36 Tais elementos nos permitem pensar em um conjunto de oposições intercambiáveis: vaca/ feminino/dentro/esquerda x boi/masculino/fora/direita, por exemplo.

37 KVIUM, Ch. Inauguration and Foundation. An Essay on Roman Ritual Classification and Continuity. In: RICHARDSON, J. H.; SANTANGELO, F. Priests and State in the Roman World. München: Franz Steiner Verlag, 2011. p. 63-90, p. 83. 
O finitor qualificava as divisões das inaugurationes: o pomerium $\mathrm{e}$ o murus são sancti, i.e., são sujeitos à lei augural (Plut. Quaest. Rom. 27). O fundador, contudo, não é um sacerdote: é um magistrado e guerreiro e usa o cinctus Gabinus, modo de arrumar a toga usado em rituais religiosos. Seu murus estabelece um ager effatus num local exterior (fori), que não é somente o domínio estrangeiro dos deuses (pars hostilis), mas também o domínio da guerra, militiae. Uma parte é doméstica, pars familiaris, e pertence ao nascimento e à vida, onde os mortos serão estritamente proibidos (uma reiteração das leges de colônias); a outra é pars hostilis, esfera da morte e da guerra. O finitor põe os coloni no interior de uma ciuitas que foi condita (posta num lugar, reunida) e, ao criar portas em seu murus, o agora conditor cria o espaço de transição entre as esferas da urbs e do ager: os mortos podem passar por elas, pois não são sanctae, permitindo também que os guerreiros, ritualmente purificados, possam retornar e que deuses euocati possam ser incorporados e instalados na nova cidade.

Poderíamos nos perguntar se o ritual de fundação e as técnicas da limitatio realmente seguiam padrões religiosos ou se os escritores romanos - da República tardia e do principado - trataram de explicar tais métodos a partir de paralelos visíveis com as práticas rituais da inauguratio. Seja como for, os rituais de fundação eram verdadeiros palcos de comunicação e publicização de ações e criações político-institucionais e as analogias provavelmente faziam sentido para os romanos. Sua reiteração poderia resultar na criação de novas práticas ou na modificação de antigas, alterando, ressignificando e consolidando novos conhecimentos e práticas religiosas, políticas e administrativas de um modo tal que as inovações ganhavam ares de antiguidade, autoridade e realidade, e a ordem romana tornava-se ordem sagrada.

Recebido em setembro de 2012. Aprovado em junho de 2013. 